Rev. Adm. Saúde - Vol. 18, № 73, out. - dez. 2018

http://dx.doi.org/10.23973/ras.73.141

ARTIGO DE REVISÃO

\title{
Subsídios para o marketing pessoal do enfermeiro
}

Subsidies for nurses' personal marketing

\section{Beatriz Sarmento Molina1, Daniela Ferreira dos Santos², Patricia Bover Draganov $^{3}$}

\section{1, 2. Graduanda de enfermagem. Universidade Anhembi Morumbi, São Paulo SP}

2. Enfermeira e arquiteta, doutora em ciências. Docente da Universidade Anhembi Morumbi, São Paulo SP

\section{RESUMO}

Introdução: O marketing pessoal traz uma possível contribuição para a imagem do enfermeiro, desmistificando a imagem de um serviço submisso, hoje, ainda marcada por momento da história da profissão. Objetivo: Apontar os subsídios para o desenvolvimento do marketing pessoal e seus benefícios para o enfermeiro. Método: Revisão bibliográfica, em que a amostra final foi constituída por 3 livros, 19 arquivos que foram planilhados e categorizados. Resultados: As manifestações de preconceito foram apontadas em diversos momentos históricos e até os dias de hoje. A utilização dos subsídios do marketing é utilizada por enfermeiros na construção da imagem profissional em favor da enfermagem. Conclusão: A revisão literária poderá despertar o interesse por novas pesquisas, aprofundando questões e problematizações que envolvam as percepções sobre a temática exposta.

Palavras-chave: Subsídios, Marketing pessoal, Enfermeiro, Status.

\section{ABSTRACT}


Introduction: The personal marketing brings a possible contribution to the nurse's image, by demystifying the image of a submissive work, today, still marked by the moment of this profession's history. Goal: To point out the subsidies for the personal marketing's development and its benefits for the nurse. Method: Bibliographical review, in which the final sample consisted of 3 books, 19 articles and monographs. Results: The demonstration of prejudice was pointed out in several historical and even current moments. The application of the marketing's subsidies is used by nurses in the building of its professional image in favors of the nursing. Conclusion: The literature review could evoke the interest in new researches, deepening questions and descriptions that involve the perceptions of the presented theme.

Keywords: Subsidies, Personal marketing, Nurse, Status.

\section{INTRODUÇÃO}

Os profissionais de enfermagem são responsáveis pela manutenção da saúde das pessoas, muitas vezes atuando em conjunto com equipes multiprofissionais.

Atualmente a enfermagem é uma profissão exigente, baseada em conhecimento científico, tendo contributos que são fundamentais para a saúde dos cidadãos. Mas, a literatura revela existir um reduzido reconhecimento social e uma visibilidade mediática baixa. A sociedade tem desconhecimento acerca do papel do enfermeiro e do valor de seus cuidados (Cardoso; 2012).

A lei 7.498, de 25 de junho de 1986, regula o exercício da enfermagem profissional. Dentre os artigos presentes - Art. 1ㅇa Art. 16으 - enaltecem as atribuições dos enfermeiros, além do exercício de enfermagem (COREN; 2018).

A enfermagem é a profissão que, na área da saúde, tem como objetivo prestar cuidados de enfermagem ao ser humano, são ou doente, ao longo do ciclo vital, e aos grupos sociais em que ele está integrado, de forma que mantenham, melhorem e recuperem a saúde, ajudando-os a atingir a sua máxima capacidade funcional tão rapidamente quanto possível (Avila, et al; 2013 e Portugal; 2011).

Como a profissão responsável pelo cuidado humano, individual e coletivo, o cuidado de enfermagem envolve a realização a assistência direta ao ser humano, a gerência dos serviços e da assistência prestada pela equipe de enfermagem, o ensino, a pesquisa e a participação política como processos de trabalho (Senna; 2007). Orienta-se por preceitos éticos e legais, de forma a assegurar a qualidade para o bem-estar das pessoas e/ou o reestabelecimento de sua saúde (Andrade; 2016). 
Pode-se definir processo de trabalho como a transformação de um objeto determinado em um produto determinado, por meio da intervenção do ser humano que, para fazê-lo, emprega instrumentos. Ou seja, o trabalho é algo que o ser humano faz intencionalmente e conscientemente, com o objetivo de produzir algum produto ou serviço que tenha valor para o próprio ser humano. O processo de trabalho em saúde tem ao mesmo tempo uma identidade de processo, é composto de uma série de processos de trabalho desempenhado por diversos agentes. Segundo citado no artigo de Maria Cristina Sanna, analogamente, na enfermagem também há mais de um processo de trabalho, que pode ou não ser executado concomitantemente. São eles: o processo de trabalho assistir, o processo de trabalho administrar, o processo de trabalho ensinar, o processo de trabalho pesquisar e o processo de trabalho participar politicamente (Sanna; 2007).

A gestão em enfermagem, por sua vez, busca no corpo teórico da ciência do marketing os conhecimentos que lhe permitam analisar, compreender a atuar no seu cotidiano profissional (Souza, et al; 2010). Ainda assim, poucos estudos atuais foram discutidos expondo subsídios para o desenvolvimento do marketing pessoal associado ao enfermeiro. Por outro lado, o marketing pessoal em determinadas áreas, é extremamente utilizado, quando aplicado de maneira coerente e planejada, atribuindo ao profissional um maior valor a sua imagem pessoal. Ou seja, o marketing é usado muito mais do que apenas se autopromover, ele é possibilidades, maneiras e meios que irão fazer parte do fortalecimento pessoal, permitindo ao interessado tornar-se referência no que este faz. Os profissionais de enfermagem, por sua vez, procuram por melhores ambientes de trabalho nos quais a proporção paciente/enfermeiro seja propícia ao desempenho de suas funções, com satisfação e segurança (Mendes; 2011).

A imagem profissional faz parte do cotidiano do enfermeiro desde o seu surgimento e se esta for eficiente e eficaz trará progressos para a vida profissional. Sendo assim, quais os subsídios para desenvolvimento do marketing pessoal e quais benefícios pode trazer para o enfermeiro?

O marketing pessoal traz a possível contribuição para a imagem do enfermeiro, desmistificando a imagem de um serviço submisso e dócil, hoje, ainda marcada por um momento da história da profissão (Andrade, Cavalcanti, Apostólico; 2017).

Esse estudo se justifica, pois, aplicar o marketing pessoal é a forma mais eficaz de administrar a própria carreira e até mesmo a vida pessoal, expondo conhecimentos e habilidades, com isso trazer o crescimento para o então sucesso profissional e ajudar no crescimento da profissão.

\section{OBJETIVO}

O objetivo deste trabalho foi apontar os subsídios para o desenvolvimento do marketing pessoal e seus benefícios para o enfermeiro. Assim, pretende-se como objetivo específico o status e a enfermagem, conceituar o marketing pessoal e após associar o marketing pessoal com o enfermeiro. 


\section{MATERIAL E METÓDOS}

O método científico utilizado neste estudo foi o de pesquisa de revisão bibliográfica, que "é desenvolvida a partir de material já elaborado, constituído de livros e artigos científicos" (Gil; 2008), a respeito dos subsídios para o marketing pessoal do enfermeiro.

A coleta de dados para este estudo foi realizada por meios de livros e artigos científicos publicados nos últimos dez anos. Foram utilizados 3 livros com conteúdo sobre história da enfermagem e marketing pessoal, em idioma português, disponíveis na biblioteca da Universidade Anhembi Morumbi, publicados entre 2008-2018.

Foram acessados 19 artigos científicos e monografias sobre a temática nas bases de dados da Scielo, LILACS, MEDLINE, BVS e BDEnf, publicados nos últimos 10 anos (2008-2018), com as palavras chaves: marketing pessoal, enfermeiro, subsídios, status e em inglês: subsidies, personal marketing, nurse, status. Foram utilizados 8 artigos nacionais, disponíveis online em texto completo.

Foi realizada a leitura analítica dos 19 artigos e o planilhamento dos dados com a finalidade de ordenar e sumarizar as informações contidas nas fontes, e mostrar de que forma o marketing pessoal pode colaborar com o enfermeiro e a conquista de status profissional.

\section{RESULTADOS}

\section{O status e a enfermagem}

Status é um conceito com vários significados, e muitos destes envolvem uma combinação de dois elementos bem diferentes. No primeiro, status se refere à estima ou desprezo, deferência ou depreciação concedida a indivíduos ou grupos percebidos como superiores ou inferiores. Nesse sentido, se refere às avaliações positivas e negativas feitas pelas pessoas sobre as outras e é sinônimo de prestígio. Como esse primeiro sentido para status diz respeito a um sentimento na mente das pessoas, remete a um aspecto especificamente simbólico da desigualdade. No segundo, status pode se referir também a posições na estrutura social, de um modo completamente independente de avaliações individuais de superioridade e inferioridade. Tal como nas escalas "puras" de status socioeconômico, por exemplo, construídas combinando uma série de atributos das ocupações (Ollivier; 2009).

A história do status da enfermagem traz consigo uma bagagem de preconceitos e visão de trabalho submisso, em que desde o surgimento da profissão é visto como um desempenho basicamente manual e exercida predominantemente, por mulheres, o que traz dentro da nossa sociedade uma proposta profissional com perfil dócil e submisso (Geovanini, et al; 2010). 
Estudando a História da Enfermagem, observou-se que a percepção distorcida e errônea da profissão, logo preconceituosa, não é um fenômeno incomum, tampouco recente, tendo sua gênese, possivelmente, a partir da secularização do processo de cuidar, iniciado com a reforma protestante (Jesus, et al; 2008).

A partir do momento em que o hospital foi concebido como um instrumento de cura e a distribuição do espaço tornaram-se um instrumento terapêutico, o médico passou a ser o principal responsável pela organização hospitalar. A inversão das relações hierárquicas no hospital, a tomada de poder pelo médico, se manifestou no ritual da visita, desfile quase religioso em que o médico, na frente, ia ao leito de cada doente seguido de toda a hierarquia do hospital: assistentes, alunos, enfermeiras, etc. Essa codificação ritual da visita, que marca o advento do poder médico, foi encontrada nos regulamentos de hospitais do século XVIII, em que se diz onde cada pessoa deve estar colocada, que o médico deveria ser anunciado por uma sineta, que a enfermeira deveria estar na porta com um caderno nas mãos e deveria acompanhar o médico auxiliando-o no que fosse solicitado (Costa, et al; 2008).

Observou-se que a enfermagem brasileira foi sustentada pelo sistema de formação categorizada e que, ao mesmo tempo, atendia às necessidades do mercado, o que reforçava a fragmentação e a subdivisão do trabalho na área. Assim, formou-se uma nova pirâmide hierárquica, em que o vértice era ocupado pelos enfermeiros e a base pelos auxiliares e técnicos de enfermagem. Com essa divisão determinava-se que os técnicos e auxiliares fiquem com o cuidado direto do cliente, limitando os Enfermeiros às funções burocráticas e administrativas (Geovanini, et al; 2010).

É importante ressaltar que a divisão do trabalho dificultava também o seu reconhecimento social, uma vez que os usuários dos serviços desconhecem essa divisão hierárquica e tendia a confundir os seus agentes. Isso acontecia, pois existiu várias vertentes, um deles era dos servidores que se autodenominavam "Enfermeiros", pelos próprios Enfermeiros que não se aperfeiçoavam continuamente, pela população e por fim, pela imagem histórica que existe da profissão, ora como grotesca e vulgar, ora como dócil e submissa, fortalecendo ideias pré-concebidas e errôneas a seu respeito, contribuindo para a perpetuação de uma imagem que desfavorecia o status do profissional da enfermagem e seu poder da barganha da enfermagem e defesa de seus interesses (Geovanini, et al; 2010).

Ainda hoje a enfermagem é vista como subalternamente indispensável, pois a sociedade, que necessita ver os papéis de homem e mulher firmemente delimitados, resgata para essa profissão a mesma responsabilidade que sempre foi atribuída à mulher; qual seja zelar pelo bom relacionamento na equipe, assim como a responsabilidade para permitir ao médico assistir o paciente sem preocupar-se com detalhes menos gloriosos, como manter o paciente limpo e confortável. Consequentemente, os profissionais repetem quase que à exaustão a ideologia de que o médico estudou mais, ou o fato de ele ser homem, sugerindo uma atitude de intimidação por falta de argumentos para dizer, por exemplo, "Dr., esta é a sua especialidade, mas este é o procedimento para o qual estou qualificada", a fim de marcar nossos espaços, derrubar barreiras e contribuir para o auto respeito (Jesus, et al; 2008). 
A forma como os profissionais comportam-se no ambiente de trabalho e na sociedade, em meio à visibilidade de outros indivíduos sendo usuários de tais serviços ou outros profissionais atuantes no mesmo âmbito, define o status de uma determinada profissão. Assim sendo, o status, neste estudo, é compreendido como o entendimento da aceitação e pertinência de uma função dentro de um período histórico desta profissão, neste caso, o período atual, e como esse status influencia a profissão em si e se adéqua ao ambiente onde atual (Freidson; 2009).

Assim do ponto de vista sociológico acerca das profissões, o status é considerado como posição de importância da profissão reconhecida pela sociedade com base na sua técnica e legalidade exercida no trabalho (Freidson; 2009).

Ao longo dos anos a enfermagem vê sua imagem vinculada a dois polos: $O$ primeiro de ciência, algo que foi desvinculado como tarefa a partir de estudos e pesquisas, profissão que necessita de grande técnica e aptidão para tal função, status adquirido por meio de vários fatores como o aumento nas atribuições do enfermeiro, que foi somente previsto após uma melhor capacitação e estudos de pesquisas (Bardin; 2010), o aumento do academicismo da enfermagem gerando profissionais mais competentes e aumento na concorrência dentro da profissão algo que aumentou o número de profissionais na área fazendo com que a necessidade na capacitação constante fosse aumentada (Kleba, Ribeiro, Machado; 2010).

O segundo polo é da distância e falta de identidade, ou seja, quanto maior é a pesquisa na área, maior é o trabalho feito nos hospitais e afins e, menor é a visibilidade da profissão na sociedade, sendo nas mídias ou nas comunidades em geral. Dentro dos próprios hospitais a enfermagem ainda carrega uma imagem submissa ou tímida voltando esforços para se auto afirmar como parte predominante nos serviços de saúde (Kleba, Ribeiro, Machado; 2010).

Considerando somente com o fato de que $90 \%$ dos trabalhos feitos na área de saúde são realizados pela enfermagem, já seria suficiente para que a classe se reafirmasse como pilar indispensável no seu meio e assim adquirir o status condizente com a sua importância no mercado, ainda assim a enfermagem carece de empoderamento, sendo refém do contexto histórico que viveu ou pela desvalorização social que existe nos modelos de assistência a saúde. No Brasil principalmente nos serviços particulares (Kleba, Ribeiro, Machado; 2010).

A hospitalização da enfermagem se deu pelo aumento da capacidade dos hospitais de gerir e manter internações, além de precisar de sua técnica em situações de urgências e emergência. Isto foi de certa forma afastando a enfermagem da comunidade, fazendo com que a imagem que antes era de uma profissão presente no cotidiano da população fosse transformada na profissão que só seria valorizada quando houvesse uma enfermidade e necessidade de utilização dos serviços de saúde, fato que, dentre outros fatores, acontece pela influência do Estado na saúde, destinando mais verba nos serviços especializados e de manutenção do que na prevenção, área que a 
enfermagem sempre foi muito atuante, porém menos a cada dia (Andrade, Schaker; 2011).

O status da enfermagem moderna varia entre a evolução intra-hospitalar e a ausência extra-hospitalar, sendo mais prestigiada academicamente do que lembrada socialmente. O enfermeiro sempre terá sua imagem vinculada ao trabalho duro, manual e desvalorizado e a tenacidade de prestar um serviço vital para a sociedade, mas por enquanto procura sua definir identidade e busca a valorização e o prestígio por ser a profissão mais atuante na saúde da população (Freidson; 2009).

\section{Marketing pessoal}

Para começar, é preciso agregar o conceito básico de marketing - market (mercado) + ing (gerúndio), "mercadeando" ou "mercadando", palavras que não existem, logo, não há tradução literal. Pode-se dizer que o marketing é o estudo do mercado, seja de produtos (sapatos, roupas, cosméticos, etc.) ou de serviços (telefonia, consórcios, hospitais, etc.) (Kotler; 2010).

Segundo a AMA (American Marketing Association) marketing é a atividade, conjunto de instituições e processos para criar, comunicar, entregar e trocar ofertas que tenham valor para clientes, parceiros e sociedades em geral. A pesquisa de marketing é a função que liga o consumidor, o cliente, e o público ao profissional do marketing por meio de informações - informações usadas para identificar e definir oportunidades e problemas; gerar, refinar e avaliar ações de marketing; monitorar o desempenho, e melhorar a compreensão do marketing como um processo. A pesquisa de marketing especifica as informações necessárias para abordar esses problemas, delineia o método de coleta de informações, gerência e implementa o processo de coleta de dados, analisa os resultados e comunica os resultados e suas complicações (AMA; 2013).

Sendo uma função organizacional, o conhecimento e aplicação do conceito de marketing devem permear todas as áreas da organização, incluso a organização pessoal. Apesar de se conhecer práticas de marketing de produtos e de serviços desde antes de 7.000 a.C., a disciplina de marketing tem menos de um século de existência. A análise desse período possibilita identificar os desenvolvimentos e retrocessos da teoria e prática em marketing, bem como traçar o seu papel no futuro (Frederico; 2008).

Para Philip Kotler, o autor conhecido como o "pai do marketing moderno", o marketing é mais do que um departamento de uma empresa: é um modo ordenado e profundo de refletir sobre mercados e planejar para eles. Este processo não se aplica somente a bens e serviços. O processo se inicia com a pesquisa de mercado, de modo a compreender sua dinâmica e identificar oportunidades para atender às necessidades existentes ou latentes (Kotler; 2010). 
Já o marketing pessoal, além de servir como forma de se autopromover, aparece como uma oportunidade na garantia do emprego em tempos difíceis, ou seja, conjunto de ferramentas utilizadas em benefício da própria carreira (Pereira, Souza; 2017).

A definição de marketing pessoal não se trata somente de autopromoção de uma categoria profissional, por isso, a definição correta de marketing pessoal é a que trata dessa modalidade como utilização de fundamentos de marketing em benefício da carreira ou da vida pessoal, e não necessariamente por motivos financeiros. É decisivo mapear as qualificações, quais as características marcantes, pontos para melhora, as forças, o que deve ser desenvolvido, desmistificar as fraquezas. Esse processo é conhecido como matriz SWOT, ou matriz FOFA, como adaptado para o Brasil. Esse instrumento que diagnostica a atual situação, no caso do marketing pessoal, analisa 0 momento do profissional para ajudar a elaborar o planejamento pessoal (Harada; 2011). A matriz SWOT pode ser observada na Figura 1.

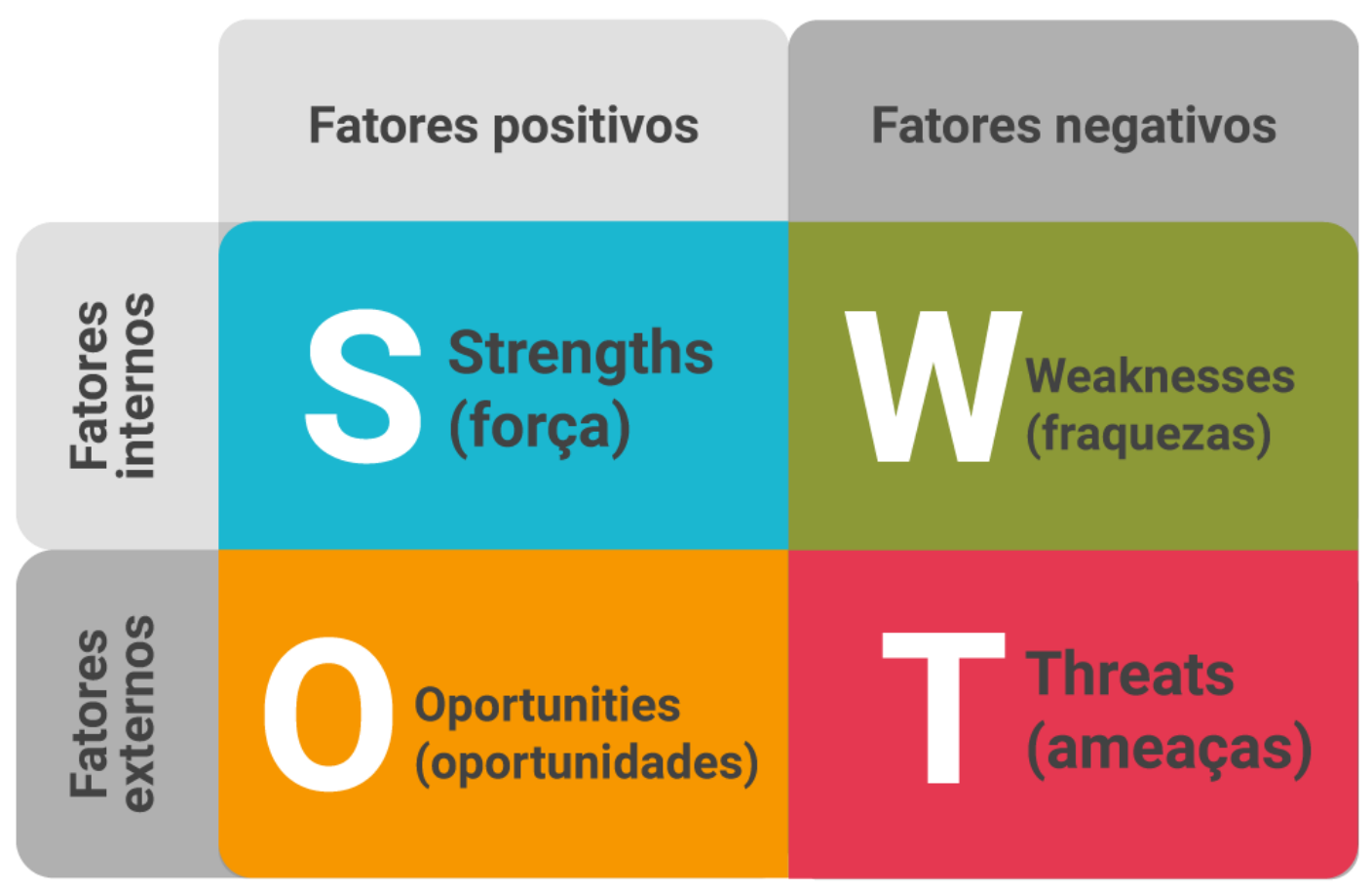

Figura 1. Analise de matriz SWOT. Fonte: https://marketingdeconteudo.com/como-fazer-uma-analise-swot/

A sigla SWOT vem das iniciais das palavras inglesas: STRENGHTS (forças), WEAKNESSES (fraquezas), OPPORTUNITIES (oportunidades), THREATS (ameaças). Estes são justamente os pontos a serem analisados. Uma das partes da análise SWOT é o estudo do ambiente externo à organização em busca de ameaças e oportunidades. Trata-se da análise daquilo que está sempre fora do controle das empresas, mas que é importante de se conhecer e monitorar. A outra parte da análise SWOT, trata dos pontos fortes e fracos da 
organização, ou seja, de seu ambiente interno. Assim, quando se percebe um ponto forte, devemos ressaltá-lo ainda mais e quando percebemos um ponto fraco, devemos agir para corrigi-lo ou pelo menos para minimizar os seus efeitos (Santos; 2016).

\section{DISCUSSÃO}

\section{Marketing pessoal e o enfermeiro}

O marketing é uma das mais importantes estratégias para favorecer a visibilidade de uma profissão. Para compreender o marketing pessoal é necessário agregar conceitos do marketing à profissão (Mendes, et al; 2011).

No âmbito da enfermagem, podemos pressupor que a inabilidade da profissão ao valorizar seus profissionais, ameaça a sua própria visibilidade, desta maneira entendemos que a enfermagem precisa ter um posicionamento mais proativo neste cenário, valendo-se de evidências para reivindicar melhores condições e valorização. Automaticamente, é necessário mostrar o seu valor e sua competência para o sistema, para seus clientes, ou seja, utilizar o marketing pessoal, alcançando visibilidade social (Mendes, et al; 2011).

Para alcançar o sucesso profissional, deve-se ter uma carreira consolidada, e ter planos concretos de onde-se quer chegar. Aplicar o marketing pessoal no dia a dia é a maneira mais eficaz de conduzir a própria carreira, destacando técnicas e conhecimentos profissionais. Para decolar a carreira, é necessário primeiramente buscar aprimoramento e capacitação, deixar o currículo sempre disponível e atualizado em sites de consultas, como a plataforma Lattes (lattes.cnpq.br) que é base de dados de currículos e de instituições das áreas de ciência e tecnologia. Nesta era moderna, temos ainda a opção do Linkedln (www.linkedin.com), site gratuito que permite relacionamentos com todas as áreas. Outra opção é preparar uma identidade visual, como releases e cartão de visita (Harada; 2011).

Não menos importante na formação de vínculo entre o profissional e o paciente é a comunicação, que potencializa o marketing pessoal. A postura comunicacional do profissional pode resultar em satisfação e elogios de pacientes, familiares e os demais profissionais ao redor, como ressaltado no artigo brasileiro que aponta projeções para a visibilidade do enfermeiro (Andrade, Cavalcante, Apostólico; 2017).

Em entrevista pelo Conselho Regional de Enfermagem, Mario Persona (palestrante de marketing e estratégias), falou sobre marketing para profissionais de saúde: "creio que o produto do profissional de saúde não são apenas suas habilidades, mas ele próprio, tudo o que é e sabe fazer. $\mathrm{O}$ profissional de saúde é, antes de tudo, um profissional do conhecimento. O que ele vende é o que sabe sobre o cuidar de um cliente, e é preciso entender o que esses clientes esperam dele. Ele é o seu próprio outdoor, é ele o comercial na TV, é ele a página da revista. Trabalhar essa postura humana é o primeiro passo e talvez o mais importante para um profissional. Cabe ao profissional 
planejar cuidadosamente seu marketing pessoal, trabalhar o autoconhecimento e criar uma imagem que seja um espelho de suas qualidades, emponderandose" (Gentil; 2009).

Marketing pessoal não se trata apenas de dicas de autoajuda para chegar onde se deseja, mas de um bom planejamento desenvolvido, autoadministrado e aplicado no dia a dia para buscar sucesso profissional. Para ser reconhecido é preciso ser visto e admirado, e isso demanda empenho e atualização constante. Para conquistar objetivos, muitas vezes, é necessário mudar algumas atitudes e alguns hábitos pessoais, o que exige disposição e iniciativa (Harada; 2011). O marketing pessoal traz grande contribuição na construção de uma enfermagem mais fortalecida, ao passo que, se conseguir levar a sociedade uma imagem com maior credibilidade profissional, pode visibilizar uma imagem social positiva da categoria (Mendes; 2011).

Defende-se que na prática profissional do enfermeiro constitui-se o seu produto de venda, sendo que o aperfeiçoamento e aprimoramento de suas habilidades e técnicas são destaque tanto na carreira, quanto na imagem pessoal (Malagutti; 2009).

Para Sanna, envolve também manejar os 5 processos de trabalho com habilidades (Sanna; 2007). Networking é uma palavra inglesa cuja tradução para o português significa rede social, ou seja, um conjunto de pessoas voltadas ao mesmo interesse que funciona através de profissionais que indicam uma vaga de emprego a alguém que esteja desempregado (Petterini; 2010).

Como citado anteriormente, a análise SWOT, é uma poderosa ferramenta de marketing e deve ser utilizada durante o planejamento estratégico pessoal. A matriz apresenta 4 variáveis citadas por siglas, S: Strenghts, Forças; W: Weaknesses, Fraquezas; O: Opportunities, Oportunidades, T: Threats, ameaças (Santos; 2016).

O uso da matriz SWOT é uma das formas de se manter com sucesso no mercado justamente por conhecer as variáveis e permitir planejamento; são meios para atingir objetivos. Cabe a cada profissional se adaptar a matriz SWOT, enaltecendo as variáveis internas e externas do seu ambiente profissional (Mendes, et al; 2011). Como podemos observar na Figura 2. 


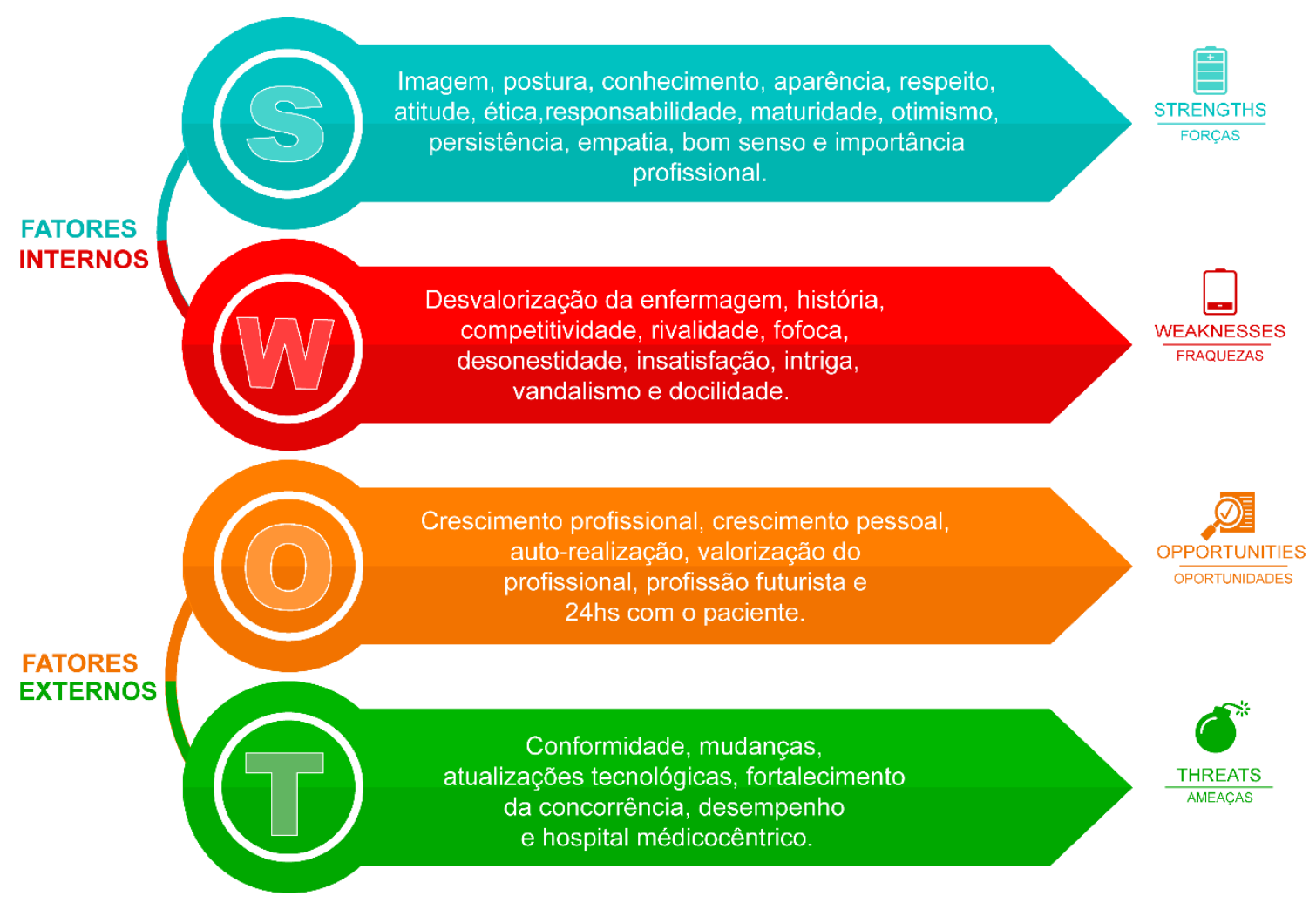

Figura 2. Análise SWOT na enfermagem.

Tudo deve ser construído sobre uma base solida de conhecimento técnico, científico e cultural. Apesar da vantagem competitiva, por conta desse planejamento, não se pode descuidar, pois marketing pessoal, diferentemente de serviços e de produtos, se for malfeito, pode denegrir a imagem profissional e pessoal, o que é infinitamente mais difícil de consertar (Harada; 2011).

O enfermeiro deve reconhecer que o marketing no exercício de sua profissão tem se tornado algo natural, e necessário para a realização pessoal e a excelência da assistência prestada levando em consideração que as práticas de enfermagem, em sua maioria, devem ser voltadas ao paciente, na busca de reconhecer e suprir suar necessidades, o que transmite ao cliente aquilo que o profissional tem de melhor, promovendo um relacionamento embasado na confiança (Souza, Sousa; 2012).

O marketing pessoal, atualmente, é uma importante ferramenta para a visibilidade, a colocação e a ascensão profissional, devendo-se considerar seu caráter político e os valores e significados sociais, que vendem juntamente com sua imagem (Gomes, Setton; 2016).

Embora ainda que de forma tímida, a enfermagem tem usado o marketing para aumentar a visibilidade da profissão. Na busca pela satisfação pessoal e de seus clientes, atua por meios de comunicação, SWOT, networking, capacitação 
profissional, atualização de currículo, portfólio e divulgação de conhecimentos científicos desenvolvidos ao longo dos anos de história da profissão (Andrade, Cavalcante, Apostolico; 2017).

A aplicação da matriz SWOT mostrou-se exitosa, proporcionando a compreensão dos fatores influenciadores, assim como a apresentação da forma como eles podem afetar o processo de trabalho. Além disso, contribuiu na medida em que possibilitou traçar metas de intervenção para melhoria do setor e, consequentemente, da assistência e marketing, prestados pela enfermagem (Mendes, et al; 2016).

\section{CONCLUSÃO}

Este estudo permitiu conhecer os subsídios necessários para o desenvolvimento dos enfermeiros utilizando o marketing pessoal.

Marketing pessoal pode ser definido como uma estratégia individual para atrair e desenvolver contatos e relacionamentos interessantes do ponto de vista pessoal e profissional, bem como para dar visibilidade a características, habilidades e competências relevantes na perspectiva da aceitação e do reconhecimento profissional, além é claro, do pessoal.

Para o enfermeiro é muito difícil criar uma imagem que seja um reflexo de sua qualidade. Não que o enfermeiro não possua qualidades; ele tem consciência delas, mas porque tem inculcado, de forma até inconsciente, que seu trabalho é caridade, abnegação e submisso, portanto, não é passível de ser divulgado, e muito menos para promover o marketing pessoal.

Somos todos responsáveis em construir a nossa história. Portanto, é imprescindível que os profissionais sejam capazes de identificar e refletir sobre os prejuízos e tradições que perpetuam na enfermagem, no sentido de superálos. Trabalhar a postura humana e profissional é o primeiro passo, e talvez o mais importante, para melhorar o marketing do enfermeiro junto à sociedade.

Espera-se, contribuir com o enriquecimento da literatura, além de expor a necessidade do marketing aos colaboradores, que muitas vezes, estes, não sabem como inserir a teoria do marketing pessoal na prática em seu dia a dia, além de incentivar mais pessoas a estudarem acerca do tema desenvolvido.

Sugerem-se, como estudos de continuidade, pesquisas que desenvolvam e apliquem matrizes SWOT e o marketing pessoal para verificar aspectos detalhados da construção da imagem profissional em prol da enfermagem.

\section{REFERÊNCIAS}

1. KOTLER, Philip. Marketing 3.0: As forças que estão definindo o novo marketing centrado no ser humano. Rio de Janeiro: Elsevier, 4⿳亠丷a impressão, 2010. 
2. PEREIRA, Carlos Eduardo; SOUZA, Nayara Silva. Revista Saúde e Desenvolvimento: A Importância do Marketing Pessoal para os Profissionais da Área da Saúde. Vol. 11, n. 9, 2017. Disponível em: < https://www.uninter.com/revistasaude/index.php/saudeDesenvolvimento/arti cle/view/802/494>. Acesso em: 25 de outubro de 2018.

3. HARADA, Maria de Jesus, organizadora. Vários autores. Gestão em Enfermagem: Ferramenta para Prática Segura. São Caetano do Sul, SP. Editora Yendis, 2011.

4. ANDRADE, Josilvaldo Barreto; CAVALCANTE, Maria de Belém; APOSTÓLICO, Maíra Rosa. Marketing pessoal e enfermagem: Projeção para a visibilidade social do enfermeiro. Enfermagem em foco, v.8, n.1, p. 82-86, 2017. Disponível em:

<http://revista.confen.gov.br/index.php/enfermagem/article/view/946>. Acesso em: 28 de outubro de 2018.

5. GENTIL, Rosana Chami. O enfermeiro não faz marketing pessoal: a história explica por quê? Rev. bras. enferm. Brasília, v. 62, n. 6, p. 916-918, 2009. Disponível em: $<$ http://www.scielo.br/scielo.php?script=sci_arttext\&pid=S0034$71672009000600019 \&$ Ing=en\&nrm=iso $>$. Acesso em: 28 de outubro de 2018.

6. MENDES, Isabel Amélia Costa et al. Marketing profissional e visibilidade social na enfermagem: uma estratégia de valorização de recursos humanos. Texto contexto - enferm. Florianópolis, v. 20, n. 4, p. 788-795, 2011. Disponível em: <http://www.scielo.br/scielo.php?script=sci_arttext\&pid=S0104$07072011000400019 \&$ Ing=en\&nrm=iso $>$. Acesso em 21 de outubro de 2018.

7. REFERÊNCIA FIGURA 1: Análise SWOT da matriz F.O.F.A.: entenda o conceito e como colocá-lo em prática, 2018. Disponível em:

$<$ https://marketingdeconteudo.com/como-fazer-uma-analise-swot/>. Acesso em 28 de outubro de 2018.

8. AMA - American Marketing Associations. Disponível em: <https://www.ama.org/AboutAMA/Pages/Definition-of-Marketing.aspx>. Acesso em 02 de novembro de 2018.

9. FREDERICO, Elias. O que é marketing? Antenna Web - Ed.4, 1 semestre, 2008. p.1-8. Disponível em:

<https://www.antennaweb.com.br/edicao4/artigos/pdf/ed4.pdf>. Acesso em 02 de novembro de 2018.

10. PETTERINI, Francis Carlo. Mais amigos implica em mais chance de emprego? Uma proposta de análise empírica usando a Teoria de Matching. In: Encontro Regional de Economia, n.13, 2010. ANPEC Sul. Porto Alegre, RS. 2010. 
11. SOUZA, C.G.S. O Enfermeiro e seu Marketing Pessoal e Profissional: Encantando o Paciente. Gestão no serviço de enfermagem no mundo globalizado. Rio de Janeiro: Editora Rubio, 2009. p.143-150.

12. SOUZA, F. A., SOUSA J. A. Marketing pessoal e networking como sinônimos de inserção do enfermeiro ao mercado de trabalho. JIC: Jornada de pesquisa e iniciação científica, 2012. Disponível em:

<http://ceres.facer.edu.br/anais/index.php/jic/article/view/8>. Acesso em 02 de novembro de 2018.

13. SANTOS, Berenice Maria Paludo Rodrigues. Planejamento pessoal, para melhorar a aparência na hora da seleção, para uma vaga de emprego.

RACEX: revista de administração e comércio exterior, 2017. Disponível em: $<$ http://seer.faculdadejoaopaulo.edu.br/index.php/racex/article/view/79/131>. Acesso em 04 de novembro de 2018.

14. MENDES, Viviane Ramos et al. Matriz SWOT como ferramenta estratégica no gerenciamento da assistência de enfermagem: um relato de experiência em um hospital de ensino. Revista eletrônica Gestão \& Saúde, v.7, n.3, Pág. 1236-1243, Agos. 2016. Disponível em:

<http://periodicos.unb.br/index.php/rgs/article/view/21992>. Acesso em: 03 de nov. 2018.

15. GOMES, Elias Evangelista; SETTON, Maria da Graça Jacintho. Marketing e Educação política: um estudo sobre agentes, estratégias e interpretações da cultura. Educ. Real. 2016, vol.41, n.3 pp.853-872. Disponível em: <http://www.scielo.br/scielo.php?script=sci_arttext\&pid=S2175$62362016000300853 \& \mid n g=e n \& n r m=i s o>$. Acesso em: 04 de novembro de 2018.

16. FREIDSON, Eliot. Profissão médica: um estudo de sociologia do conhecimento aplicado. Porto Alegre (RS): Sindicato dos Médicos; 2009.

17. BARDIN, Laurence. Análise de conteúdo. Lisboa (Pt): Edições 70; 2010.

18. ANDRADE, Silvana Regina; SCHAKER, Lisara Carneiro. Conhecimento do cliente sobre a atuação do enfermeiro. Revista conhecimento online, ano 3, vol. 2, setembro, 2011. Disponível em: <http://www.feevale.br/site/files/documentos/pdf/58651.pdf> Acesso em: 19 de outubro de 2018.

19. COSTA, Roberta et al. Foucault e sua utilização como referencial na produção científica em enfermagem. Texto contexto - enferm., Florianópolis, v. 17, n. 4, p.629-637. Disponível em:

<http://www.scielo.br/scielo.php?script=sci_arttext\&pid=S0104$07072008000400002 \&$ Ing $=$ en\&nrm=iso $>$. Acesso em 02 de novembro de 2018.

20. GEOVANINI, Telma; MOREIRA, Almerinda; SCHOELLER, Soraia; MACHADO, Wiliam. História da enfermagem: versões e interpretações. Rio de Janeiro, 3.ed., p.37-40, 2010. 
21. JESUS, Elaine; MARQUES, Leoana; ASSIS, Luana; ALVES, Taisy; FREITAS, Genival; OGUISSO, Taka. Preconceito na enfermagem percebido por enfermeiros: uma abordagem quantitativa. REME - Rev. Min. Enferm.; p. 477-482, out/dez., 2008. Disponível em: <http://www.reme.org.br/artigo/detalhes/291>. Acesso em: 10 Set 2018.

22. OLLIVIER, Michèle. Status em sociedades pós-modernas: a renovação de um conceito. Lua Nova, 2009, n.77, p.41-71. Disponível em: < http://www.scielo.br/scielo.php?script=sci_arttext\&pid=S0102$64452009000200002 \& l a n g=p t>$. Acesso em 04 de nov de 2018.

Recebido: 13 de novembro de 2018. Publicado: 28 de dezembro de 2018

Correspondência: Daniela Ferreira dos Santos. E-mail: dani.marsh@hotmail.com

Conflito de Interesses: os autores declararam não haver conflito de interesses.

(C) This is an Open Access article distributed under the terms of the Creative Commons Attribution License, which permits unrestricted use, distribution, and reproduction in any medium, provided the original work is properly cited 